\title{
Valoración ecosistémica a partir del uso de métricas de paisaje aplicando sistemas de información geográfica en cultivos de palma africana
}

\author{
Assessment ecosystem based on the use \\ of metrics of landscape using geographic \\ information systems in African palm crops
}

\author{
Valorização do ecossistema, a partir do uso de méticas \\ da paisagem, aplicando sistemas de informação \\ geográfica em cultivos de palma africana
}

Claudia Mayelly Ramírez Cano

Ingeniería Ambiental, Especialista en Manejo de Recursos Naturales, Magister en Desarrollo Sustentable y Gestión Ambiental

Universidad Piloto de Colombia

Claudia-ramirez1@upc.edu.co

\section{Resumen}

La valoración del paisaje es una herramienta que contribuye en los procesos de gestión y planificación mediante la generación de indicadores que permiten caracterizar las condiciones del territorio. En esta investigación se analizaron las métricas de paisaje a partir de: área de la clase (CA), área total del paisaje (TA), porcentaje del área total del paisaje (PLAND), número de parches de la clase (NP) y densidad de parches (PD), relación área-perímetro promedio (MPAR), índice de diversidad de Shannon (SDI) e índice de equitatividad de Shannon (SEI) y la valoración se realizó con la adaptación metodológica de los autores Paula Másmela y Alejandro Gómez, dicha adaptación permitió discernir sobre las características y calidad del paisaje en el municipio de Puerto Wilches, Santander, Colombia, durante el periodo entre 1987 y 2015. La valoración paisajística se realizó a partir de imágenes de satélite mediante análisis multitemporal de las coberturas para cuantificar y caracterizar las transformaciones paisajísticas dadas en el territorio. Los resultados obtenidos muestran que en el año 1987 el paisaje era más dinámico, constituido por variedad de coberturas y ecosistemas; mientras en 2015 existe una implementación a gran escala del monocultivo de palma africana que rompe con la estructura paisajística, sin embargo, el resultado de calidad visual arrojó clasificación media, que evidencia la importancia de realizar una revisión a fondo sobre las actuales políticas de ordenación del territorio.

Palabras clave: métricas de paisaje, monocultivos, tecnología satelital, valoración paisajística 


\section{Abstract}

Assessment of the landscape is a tool that helps in the processes of management and planning through the generation of indicators that allow to characterize the conditions of the territory. This research analysed the landscape starting from metrics: area of the class (CA), total area of the landscape (TA), percentage of the total area of the landscape (PLAND), number of patches (NP) class and density of patches (PD), relationship area-perimetro average (MPAR), index of diversity Shannon (SDI) and evenness of Shannon (SEI) index and assessment was carried out with the methodological adaptation of the authors Paula Másmela and Alejandro Gómez, such adaptation enabled to discern on the characteristics and quality of the landscape in the municipality of Puerto Wilches, Santander, Colombia, during the period between 1987 and 2015. The landscape assessment was performed using multi-temporal analysis of coverage satellite imagery to quantify and characterize the landscape transformations given in the territory. The results show that in 1987 the landscape was more dynamic, consisting of variety of coverages and ecosystems; while in 2015 there is an implementation to large-scale monocultures of oil palm that breaks with the landscape structure, however, the result of visual quality yielded an average rating, which demonstrates the importance of a thorough check on the current policies on the management of the territory.

Key-words: metric landscape, monocultures, satellite, landscape assessment technology.

\section{Resumo}

A valorização da paisagem é uma ferramenta que contribui para os processos de gestão e planejamento através da geração de indicadores que permitem caracterizar as condições do território. Nesta pesquisa, as métricas da paisagem foram analisadas a partir de: área da classe (CA), área total da paisagem (TA), porcentagem da área total da paisagem (PLAND), número de patches da classe (NP) e densidade de patches (PD), relacionamento, zona de perímetro, média (MPAR), índice de diversidade de Shannon (SDI) índice de equitatividade de Shannon (SEI) e valorização se realizou com a adaptação metodológica dos autores Paula Másmela e Alejandro Gómez, essa adaptação permitiu discernir sobre as características e qualidade da paisagem no município de Puerto Wilches, Santander, Colômbia, durante o período entre 1987 e 2015. A valorização paisajística se realizou a partir de imagens de satélite em análise multitemporal das coberturas para quantificar y Caracterizar as transformações paisajísticas dadas no território. Os resultados obtidos mostram que no ano 1987 a paisagem era mais dinâmica, constituída por uma variedade de coberturas e ecossistemas; Enquanto em 2015 existe uma implementação em grande escala do monocultura de palma africana, quebrando com a estrutura paisajística, porem, o resultado de qualidade visual mostrou classificação média, o que evidencía a importância de executar uma revisão em profundidade sobre as políticas atuais de ordenação de Territorio

palavras chave: métrica da paisagem, as monoculturas, tecnologia de satélite, valorização paisajística

\section{Introducción}

La relación sociedad-naturaleza conjuga diferentes percepciones e imaginarios que dependen de la funcionalidad del espacio entorno a las necesidades y consideraciones de cada comunidad. Por cuanto el análisis integral del paisaje puede identificarse como el conjunto de interrelaciones derivadas de la interacción entre geomorfología, clima, vegetación, fauna, agua y modificaciones antrópicas (Dunn, 1974; MOPT, 1993). De tal manera, que las transformaciones al territorio modifican la perceptibilidad y valoración de los espacios ya que existe una vulnerabilidad visual, lo cual puede considerarse como una plusvalía territorial (Serrano, 2015), es así que este tipo de análisis puede ser considerado como indicador o fuente de información del territorio (Forman \& Godron, 1986) 
ya que integra características intrínsecas en la relación del ser humano con el entorno.

En este sentido y dadas las actuales condiciones del medio natural, la valoración del paisaje ha adquirido gran importancia porque contribuye en la gestión territorial con la evaluación de diferentes procesos de dinamización de los ecosistemas permitiendo la identificación e inclusión de factores que interfieren en los cambios producidos al medio, Tales como la estructura, función, conectividad (de León Mata et al., 2014) heterogeneidad e interacción así como la diversidad de coberturas y ecosistemas que integran el dinamismo territorial, no solamente con relación al medio natural sino poblacional, teniendo en cuenta la dependencia proporcional que existe entre los dos factores y que aportan al desarrollo de los mismos. Para lo cual, el análisis multitemporal elaborado a partir de sensores remotos permiten una aproximación a la zona de estudio de manera actualizada y económica, a su vez requiere de una construcción metodológica que favorezca el análisis detallado de las características del territorio en este contexto, se han realizado estudios enfocados a la aplicación de métricas del paisaje con la finalidad de cuantificar la heterogeneidad a nivel ecosistema (Hoechstetter, Walz, Dang \& Tinh, 2008; McGarigal et al., 2005). Así mismo, las diferentes metodologías para valoración de paisaje permiten analizar de manera integral las características, dinámicas y los factores importantes que han sido modificados y que afectan la calidad y diversidad ambiental.

Por consiguiente y dada la implementación a gran escala de las plantaciones de palma africana, surge la necesidad de generar un estudio detallado de las condiciones paisajísticas del municipio de Puerto Wilches, Santander, Colombia, a partir de tecnología satelital aunada con patch analyst extensión de ArcGIS® y la adaptación metodológica de dos proponentes: (Másmela, 2010), con el paisaje como elemento de la ordenación territorial, y (Gómez, 2012), con la publicación titulada el paisaje: diseño de una metodología para su análisis como indicador ambiental o cultural” (Muñoz, 2004), diagnóstico, planificación e inclusión en los procesos de toma de decisiones con el objeto de evidenciar y cuantificar la transformación paisajística en las dinámicas ecosistémicas que subsisten en el procesos del municipio.

El paisaje en el ordenamiento territorial El paisaje es un componente que alberga diferentes concepciones, entre ellas se encuentra la acotada por el Council of Europe (2000) que refieren cualquier parte del territorio tal y como lo percibe la población, cuyo carácter sea el resultado de la acción e interacción de factores naturales y/o humanos y sus interrelaciones, desde la amplitud conceptual, cabe resaltar que en la óptica humana del territorio se encierra la cosmovisión, por lo cual, es importante reintegrar a los diferentes actores en los procesos de planificación territorial si se pretende direccionar el desarrollo regional. Bajo estos argumentos y con base en las evidencias de deterioro socio-ambiental actual del país, se reconoce que los efectos ocasionados en los diferentes componentes se originan por la escasa planificación del uso del suelo y los recursos ecosistémicos los intrínsecamente poseen un valor singular por los servicios que ofrecen. Por lo anterior, esta investigación suministra información actual y veraz de las condiciones de las coberturas y usos del suelo generados en el municipio de Puerto Wilches, Santander, Colombia, ocasionadas por la expansión del monocultivo de palma africana, con el fin de contribuir en procesos de planificación acertada y fortalecida.

\section{Materiales y métodos}

El desarrollo investigativo se realizó en tres fases, la primera es la caracterización de coberturas vegetales del municipio a partir de la clasificación visual de imágenes satelitales en el software $\operatorname{ArcGIS} \circledast$ (ESRI, 2011), aplicando criterios de la metodología Corine Land Cover (IDEAM, IGAC, CORMAGDALENA, 2008) para las épocas de 1987 y 2015, la segunda fase fue la aplicación de métricas, nivel de parche, para lo cual se utilizó la extensión patch analyst del software ArcGIS\& en el cual se modelaron métricas de área, densidad, forma y diversidad, para obtener una visión general de estado del territorio, la tercera fase fue la valoración de paisaje, mediante la adaptación de dos propuestas desarrolladas por Másmela (2010) y Gómez (2012), 
con el fin de determinar las transformaciones paisajísticas originadas por los monocultivos de palma africana y de la industria palmera en la región de Puerto Wilches, Santander, Colombia.

\section{Caracterización del municipio}

El municipio de Puerto Wilches ubicado en el norte del departamento de Santander (Figura 1), tiene una extensión de $1539 \mathrm{Km}^{2}$, de los cuales el sector rural tiene un área de $1536 \mathrm{Km}^{2}$, (153 $916 \mathrm{ha}$ ) que representa el $99.8 \%$ y el sector urbano un área $3.2 \mathrm{Km}^{2}$ que representa el $0.2 \%$. (Alcaldía municipal Puerto Wilches, 2012). Las características fisiográficas del municipio permiten el desarrollo de ecosistemas de alta fragilidad como son las ciénagas y humedales, condiciones óptimas para la implementación de monocultivos de palma africana, que requieren alta disponibilidad de recurso hídrico.

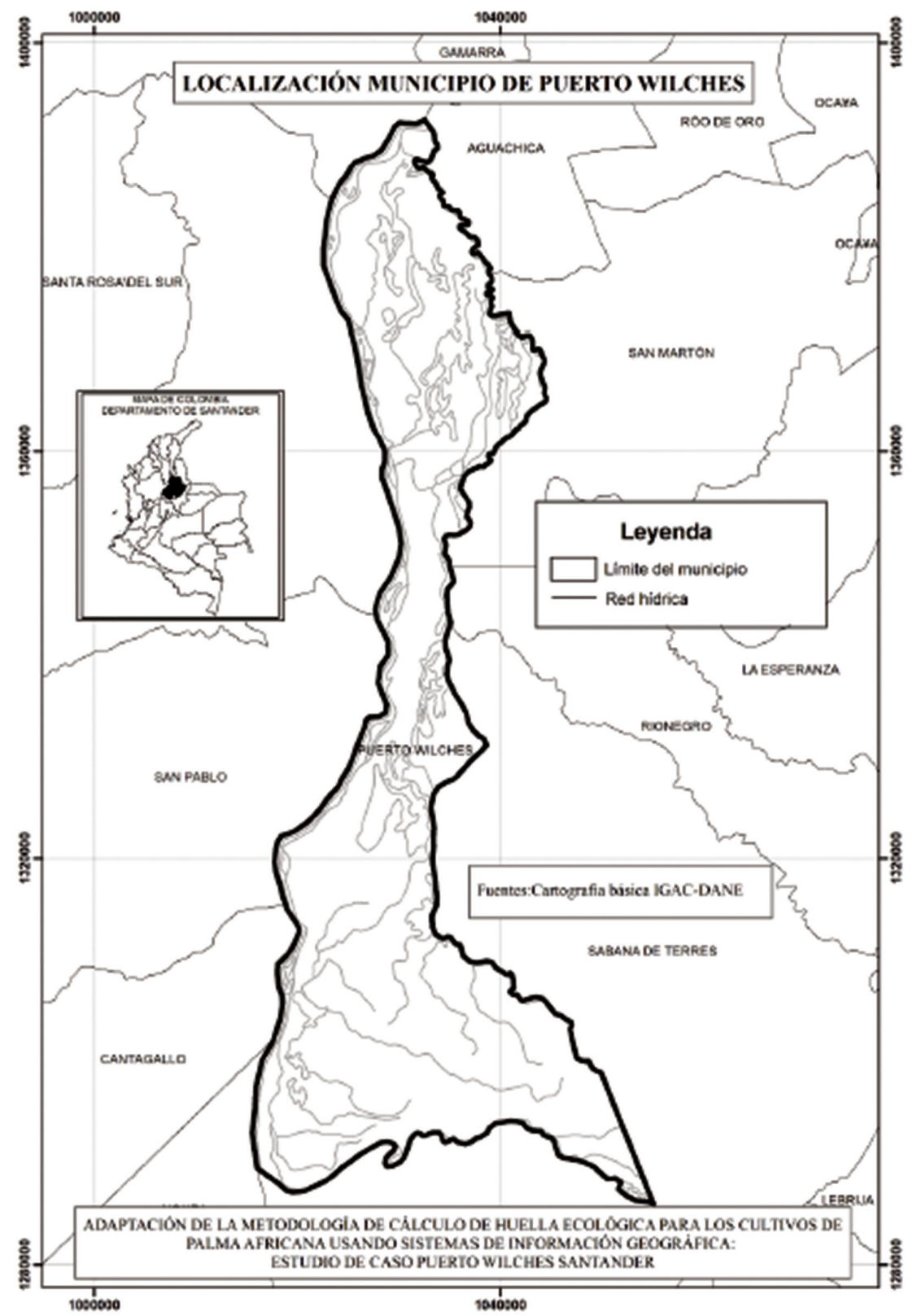

Figura 1. Mapa de ubicación geográfica del municipio 


\section{Identificación de unidades de paisaje}

La clasificación se realizó a través de imágenes de satélite Landsat TM path 8 y row 54 y 55, para los años 1987, 1991, 2010 y 2015, según el sistema mundial de referencia (WRS), tomadas de http://glovis.usgs.gov. Éstas se procesaron con los software ArcGis $10.1 ®$, donde se clasificaron las diferentes unidades de paisaje a partir del sistema de coberturas vegetales $\mathrm{CO}$ RINE Land Cover adaptado para Colombia. Las unidades de paisaje se determinaron teniendo en cuenta algunos aspectos como, el carácter específico y el valor o grado de excelencia que se les pueda atribuir, para ello es importante tener en cuenta alguno aspectos base como lo son la estructura, textura y forma (Gómez, 2012). Se realizó el análisis a cuatro décadas para evidenciar progresivamente la transformación del territorio así como el cambiante uso del suelo, sin embargo, para efectos de valoración y aplicación de métricas de paisaje solo se tuvieron en cuenta las imágenes pertenecientes a 1987 y 2015.

\section{Análisis multitemporal}

Esta fase permitió realizar una estructura del paisaje a través de la identificación de las unidades para cuantificar los diferentes elementos, dicho proceso se realizó con base en la clasificación de unidades de paisaje para los periodos de estudio, de esta manera se identificaron el grado de transformación en el uso del suelo, con la información generada se construyeron matrices de cambio.

\section{Métricas de paisaje}

Generadas para los periodos de estudio a partir del módulo patch analyst en el software ArcGis $10.1^{\circledR}$ mediante las variables de área de la clase divididas en:

Métricas de área: área de la clase (CA) área total del paisaje (TA) porcentaje del área total del paisaje (PLAND)

Métricas de densidad: número de parches de la clase (NP) y densidad de parches (PD)

Métrica de forma: relación área-perímetro promedio (MPAR)

Métricas de diversidad: índice de diversidad de Shannon (SDI) e índice de equitatividad de Shannon (SEI)

\section{Valoración paisajística}

Esta fase se desarrolló teniendo en cuenta tres dimensiones: estética, natural y productiva, enfoques que coadyuvaron en la comprensión sistemática de las transformaciones dadas en este territorio, enfocado en dos aspectos:

Método directo: bajo esta metodología la valoración se realizó a partir de la contemplación de la totalidad del paisaje, el cual se valoró directamente de modo subjetivo, utilizando escalas de rango o de orden, sin desagregarlo en componentes paisajísticos o categorías estéticas. Se midió la calidad visual del paisaje per se sin detenerse a averiguar que componentes o elementos del paisaje son causantes de su aceptación o rechazo. (Másmela, 2010)

Subjetividad Controlada: acepta que la valoración ha de ser subjetiva, pero sistemática y establecida de forma que los resultados de su aplicación en un área sean comparables, para su aplicación se utilizó una escala universal de valores del paisaje. (Másmela, 2010) Esta valoración se aplicó a la clasificación de unidades de paisaje realizada, a las cuales individualmente se le proporcionó un valor.

Herramientas para análisis: se requirieron varios componentes paisajísticos que determinaron la calidad y variabilidad del paisaje, el desarrollo de ésta adaptación metodológica se basó en los siguientes:

Biocenosis vegetal: el uso del suelo según (Gómez 1995): Se relaciona con el paisaje por el predominio de los elementos abióticos y bióticos, la presencia humana y la funcionalidad de los mismos, entorno al componente suelo y sus dinámicas, que determinan a su vez la explotación de recursos, la geografía del poblamiento, las actividades socioeconómicas, la cosmovisión, los pobladores y un sinnúmero de condiciones transformadas por la intervención antrópica sin planificación. Esta fase se realizó con base en la identificación de unidades de paisaje de las imágenes de satélite analizadas, además de lo anterior se realizó una comparación con cartografía oficial para establecer parámetros de veracidad la información generada. 
Morfología del relieve: se realizó para generar un conjunto de medidas que describen las formas topográficas, de esta manera se distinguen las diferentes formas de relieve. (González \& Moñino 2011). El análisis se llevó a cabo a partir de la información obtenida en la aplicación de tecnología satelital y usando el modelo digital de elevación con el cual se identificó las principales características morfológicas del municipio.

Desarrollos antrópicos: la intervención humana en las modificaciones paisajísticas son un factor de especial atención, ya que conllevan a la fragmentación continua de espacios naturales de importancia socio ambiental y que contribuyen en muchos casos al desarrollo desarticulado e insostenible de municipios. Dentro del contexto, se analizaron dos variables relacionadas a) caracterización por visibilidad: la valoración se realiza con base en el mapa de unidades de paisaje, teniendo en cuenta aspectos como presencia y ausencia de unidades de paisaje, variabilidad, fragilidad, representatividad, elementos dominantes, a los cuales se les asigna un valor de representatividad categorizadas en alta, medio, bajo. (Gómez, 2012). b) Caracterización por tiempo: con base en el resultado del análisis multitemporal de las unidades de paisaje se puede determinar el grado de transformación paisajística en el periodo base de estudio.

\section{Resultados}

La clasificación visual realizada al abanico de imágenes perteneciente al periodo de estudio, permitió identificar y analizar las modificaciones realizadas en el territorio objeto del presente estudio, los resultados obtenidos de la aplicación de la metodología relacionada con el análisis multitemporal de los cambios producidos en el municipio de Puerto Wilches basado en la dominancia de cobertura (Tabla 1) y la aplicación de las diferentes metodologías se obtuvieron los datos de análisis del paisaje.

Tabla 1. Representatividad de coberturas periodos 1987, 1991, 2010 y 2015.

\begin{tabular}{|c|c|c|c|c|}
\hline Tipo de cobertura & $\begin{array}{c}\text { Representatividad } \\
\text { año } 1987\end{array}$ & $\begin{array}{c}\text { Representatividad } \\
\text { año } 1991\end{array}$ & $\begin{array}{c}\text { Representatividad } \\
\text { año } 2010\end{array}$ & $\begin{array}{c}\text { Representatividad } \\
\text { año } 2015\end{array}$ \\
\hline Aeropuerto & $0.01 \%$ & $0.01 \%$ & $0.02 \%$ & \\
\hline Arbusto y matorral & $15.7 \%$ & $13.8 \%$ & $10.7 \%$ & $10.7 \%$ \\
\hline Laguna, lago y ciénaga & $5.8 \%$ & $4.3 \%$ & $3.9 \%$ & $3.9 \%$ \\
\hline Mosaico de cultivos & $0.04 \%$ & & & $0.1 \%$ \\
\hline $\begin{array}{l}\text { Mosaico de cultivos, pastos } \\
\text { y espacios naturales }\end{array}$ & $29.9 \%$ & $28.2 \%$ & $24.3 \%$ & $11.5 \%$ \\
\hline Mosaico de pastos y cultivos & $0.7 \%$ & $3.6 \%$ & $1.5 \%$ & $4.9 \%$ \\
\hline Nubes y sombras de nubes & $0.1 \%$ & & & \\
\hline Palma africana & $7.7 \%$ & $9.7 \%$ & $29.6 \%$ & $38.6 \%$ \\
\hline $\begin{array}{l}\text { Pasto enmalezado } \\
\text { y enrastrojado }\end{array}$ & $0.2 \%$ & $0.02 \%$ & $0.4 \%$ & \\
\hline Pasto limpio & $1.0 \%$ & $1.3 \%$ & $0.2 \%$ & \\
\hline Río (50m) & $5.5 \%$ & $5.4 \%$ & $4.2 \%$ & $5.3 \%$ \\
\hline Tejido urbano discontinuo & $0.2 \%$ & $0.0 \%$ & $0.1 \%$ & $0.2 \%$ \\
\hline Tierra desnuda y degradada & $0.4 \%$ & $0.2 \%$ & & \\
\hline $\begin{array}{l}\text { Vegetación acuática sobre } \\
\text { cuerpos de agua }\end{array}$ & $2.0 \%$ & $0.1 \%$ & $0.1 \%$ & $1.2 \%$ \\
\hline Zona pantanosa & $30.3 \%$ & $32.1 \%$ & $24.6 \%$ & $23.6 \%$ \\
\hline
\end{tabular}

Para esta primera década la representatividad de cobertura se relaciona con zona pantanosa y mosaico de cultivos, pastos y espacios naturales, lo cual indica que el municipio tiene una actividad económica tradicional por lo tanto su valoración paisajística tiene importancia al albergar diferentes especies y al permitir una 
dinámica del paisaje variada. Para esta época la representatividad de la palma africana comienza a tener importancia con referencia al resto de las coberturas

Para el año de 1991, la cobertura más representativa era la zona de pantanos seguido de mosaico de cultivos, pastos y espacios naturales, lo cual mantiene una dinámica paisajística similar a la de la década de los 80's sin embargo en 4 años el cultivo de palma africana alcanzó un aumento del $2.06 \%$, situación que en términos generales no alteró la dinámica del paisaje.

Con relación a las anteriores décadas en donde la representatividad era para las coberturas de mosaico de cultivos, pastos y espacios naturales y las zonas pantanosas, en el 2010 la representación de los cultivos de palma africana aumento significativamente haciendo evidente el acelerado cambio de uso del suelo en lo relacionado a la implementación de monocultivos.

Finalmente en lo corrido del año 2015, se encontró que la cobertura más representativa es la palma africana, con aumento del $9 \%$ en relación a lo evidenciado en el año 2010, este resultado infiere que en el municipio de Puerto Wilches se modificó el uso de suelo de manera abrupta y desproporcionada, afectando la calidad del paisaje de la zona argumentado en la disminución de la variedad de coberturas y las proporciones encontradas para los años 1987 y 1991. En comparación el incremento de la cobertura entre los años de 1987 y 2015 es del 30.9\% afectando de esta manera la diversidad ecosistémica de la zona. (Figura 2)

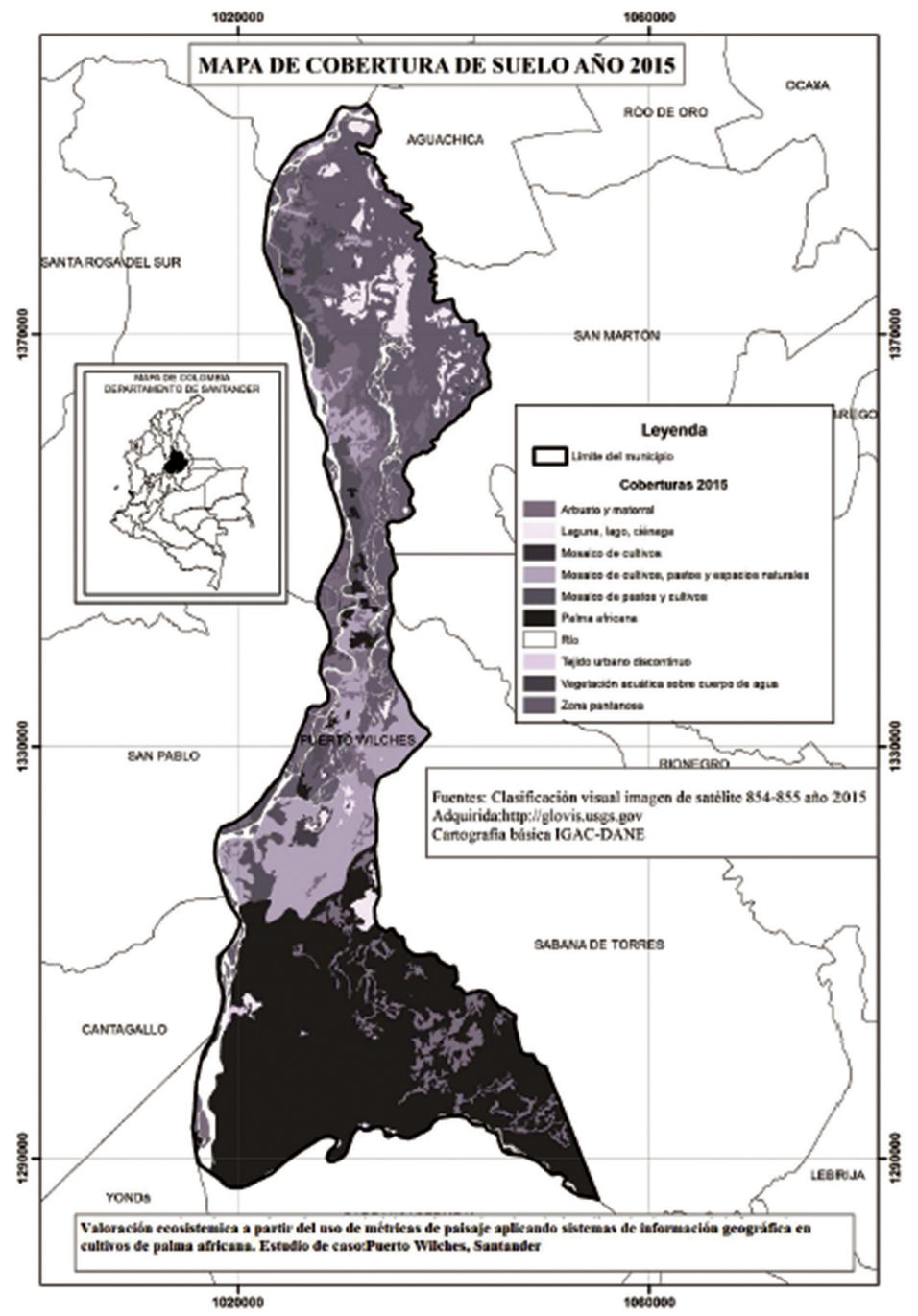

Figura 2. Mapa de coberturas del suelo año 2015 


\section{Métricas de paisaje}

El análisis realizado a través de las métricas de paisaje evidencian los cambios producidos en el territorio de Puerto Wilches, las métricas de área muestran cambios para el año 1987 el PLAND con el valor más alto correspondía a la cobertura de zonas pantanosas con un valor de $30.37 \%$ y para el año 2015 la cobertura más representativa es el cultivo de palma con un valor de $38.6 \%$. Respecto al análisis por densidad de parches para el año de 1987 los espacios naturales tales como zonas pantanosas, lagunas, lagos, ciénagas y arbusto natural tenían los valores más representativos. Para el año 2015 aunque se mantienen las mismas coberturas con los valores más altos se redistribuye el número y densidad de parches con las coberturas de intervención

En cuanto a las métricas de forma que definen la morfología y funcionalidad de los fragmentos los valores por encima de 1 se mantienen para el año 1987 en algunas coberturas, la más representativa es la vegetación acuática sobre los cuerpos de agua con 13 y para el año 2015 la cobertura artificial de pastos y cultivos es la única que supera el 1, por cuanto los índices de forma son muy bajos. En cuanto a la diversidad del paisaje los indicadores (SDI Y SEI) muestran valores bajo para el año 1987: 1,76 y 0,65 y en 20151,68 y 0,72 respectivamente, con lo cual se evidencia una homogeneidad de coberturas alta y en aumento. (Tablas 2 y 3 )

Tabla 2. Métricas de paisaje periodo 1987

\begin{tabular}{|c|c|c|c|c|c|c|c|c|}
\hline \multirow{2}{*}{ Cobertura vegetal } & \multicolumn{3}{|c|}{ Métricas de área } & \multicolumn{2}{|c|}{$\begin{array}{l}\text { Métricas de } \\
\text { densidad }\end{array}$} & \multirow{2}{*}{$\begin{array}{c}\text { Métricas } \\
\text { de forma }\end{array}$} & \multicolumn{2}{|c|}{$\begin{array}{l}\text { Métricas de } \\
\text { diversidad }\end{array}$} \\
\hline & CA_HA & TLA_ha & PLAND \% & NP & PD & & SDI & SEI \\
\hline Zona pantanosa & 46894,52 & 154398,534 & 30,37 & 114 & 0,0738 & 1,797 & 1,765822 & 0,652064 \\
\hline Laguna, lago y ciénaga & 8951,81 & 154398,534 & 5,80 & 104 & 0,0674 & 1,230 & 1,765822 & 0,652064 \\
\hline Pasto limpio & 1570,97 & 154398,534 & 1,02 & 7 & 0,0045 & 0,011 & 1,765822 & 0,652064 \\
\hline $\begin{array}{l}\text { Pasto enmalezado } \\
\text { y enrastrojado }\end{array}$ & 346,74 & 154398,534 & 0,22 & 8 & 0,0052 & 0,017 & 1,765822 & 0,652064 \\
\hline $\begin{array}{l}\text { Mosaico de pastos } \\
\text { y cultivos }\end{array}$ & 1106,81 & 154398,534 & 0,72 & 10 & 0,0065 & 0,302 & 1,765822 & 0,652064 \\
\hline $\mathrm{RIO}(50 \mathrm{~m})$ & 8519,16 & 154398,534 & 5,52 & 10 & 0,0065 & 0,756 & 1,765822 & 0,652064 \\
\hline $\begin{array}{l}\text { Mosaico de cultivos, } \\
\text { pastos y espacios } \\
\text { naturales }\end{array}$ & 46214,49 & 154398,534 & 29,93 & 44 & 0,0285 & 0,861 & 1,765822 & 0,652064 \\
\hline Palma africana & 11939,18 & 154398,534 & 7,73 & 7 & 0,0045 & 0,026 & 1,765822 & 0,652064 \\
\hline Arbusto y matorral & 24292,94 & 154398,534 & 15,73 & 58 & 0,0376 & 0,020 & 1,765822 & 0,652064 \\
\hline $\begin{array}{l}\text { Tejido urbano } \\
\text { discontinuo }\end{array}$ & 331,82 & 154398,534 & 0,21 & 3 & 0,0019 & 0,013 & 1,765822 & 0,652064 \\
\hline $\begin{array}{l}\text { Vegetación acuática } \\
\text { sobre cuerpos de agua }\end{array}$ & 3146,12 & 154398,534 & 2,04 & 9 & 0,0058 & 13,126 & 1,765822 & 0,652064 \\
\hline $\begin{array}{l}\text { Tierra desnuda } \\
\text { y degradada }\end{array}$ & 730,54 & 154398,534 & 0,47 & 10 & 0,0065 & 0,008 & 1,765822 & 0,652064 \\
\hline $\begin{array}{l}\text { Nubes y sombras } \\
\text { de nubes }\end{array}$ & 276,37 & 154398,534 & 0,18 & 7 & 0,0045 & 0,009 & 1,765822 & 0,652064 \\
\hline Mosaico de cultivos & 65,53 & 154398,534 & 0,04 & 1 & 0,0006 & 0,006 & 1,765822 & 0,652064 \\
\hline Aeropuerto & 11,53 & 154398,534 & 0,01 & 2 & 0,0013 & 0,042 & 1,765822 & 0,652064 \\
\hline
\end{tabular}


Tabla 3. Métricas de paisaje periodo 2015

\begin{tabular}{|c|c|c|c|c|c|c|c|c|}
\hline \multirow{2}{*}{ Cobertura vegetal } & \multicolumn{3}{|c|}{ Métricas de área } & \multicolumn{2}{|c|}{$\begin{array}{l}\text { Métricas de } \\
\text { densidad }\end{array}$} & \multirow{2}{*}{$\begin{array}{c}\text { Métricas } \\
\text { de forma }\end{array}$} & \multicolumn{2}{|c|}{$\begin{array}{c}\text { Métricas } \\
\text { de diversidad }\end{array}$} \\
\hline & CA_HA & TLA_ha & $\begin{array}{c}\text { PLAND } \\
\%\end{array}$ & NP & PD & & SDI & SEI \\
\hline Zona pantanosa & 36509,20 & 154322,534 & 23,66 & 85 & 0,055 & 0,026 & 1,680763 & 0,729946 \\
\hline Laguna, lago y cienaga & 6096,96 & 154322,534 & 3,95 & 92 & 0,059 & 0,018 & 1,680763 & 0,729946 \\
\hline $\begin{array}{l}\text { Mosaico de pastos } \\
\text { y cultivos }\end{array}$ & 7703,52 & 154322,534 & 4,99 & 23 & 0,015 & 1,252 & 1,680763 & 0,729946 \\
\hline $\mathrm{RIO}(50 \mathrm{~m})$ & 8077,80 & 154322,534 & 5,32 & 14 & 0,009 & 0,894 & 1,680763 & 0,729946 \\
\hline $\begin{array}{l}\text { Mosaico de cultivos, } \\
\text { pastos y espacios naturales }\end{array}$ & 17863,77 & 154322,534 & 11,58 & 12 & 0,007 & 0,110 & 1,680763 & 0,729946 \\
\hline Palma africana & 58973,59 & 154322,534 & 38,61 & 16 & 0,010 & 0,008 & 1,680763 & 0,729946 \\
\hline Arbusto y matorral & 16557,22 & 154322,534 & 10,73 & 84 & 0,054 & 0,011 & 1,680763 & 0,729946 \\
\hline Tejido urbano discontinuo & 429,63 & 154322,534 & 0,28 & 4 & 0,002 & 0,011 & 1,680763 & 0,729946 \\
\hline $\begin{array}{l}\text { Vegetación acuatica sobre } \\
\text { cuerpos de agua }\end{array}$ & 1903,06 & 154322,534 & 1,23 & 20 & 0,0129 & 0,020 & 1,680763 & 0,729946 \\
\hline Mosaico de cultivos & 207,27 & 154322,534 & 0,13 & 18 & 0,011 & 0,026 & 1,680763 & 0,729946 \\
\hline
\end{tabular}

\section{Valoración paisajística. Herramientas para análisis}

La estructura del paisaje se entiende como la relación espacial de los distintos elementos del paisaje (Forman \& Godron 1986). En lo correspondiente a los resultados de la morfología del relieve (Figura 3), se considera que el relieve del municipio de Puerto Wilches es casi homogéneo o poco montañoso, según el plan de desarrollo, la altura del $85 \%$ del municipio oscila entre 0 y $150 \mathrm{msnm}$ (Gobierno de la ciudad, 2012). Con base en lo anterior, se aplicó al modelo digital de elevación (MDE) la ponderación propuesta por Cañas (1995) donde la altitud se describe como costa con un valor asignado de 6 . 


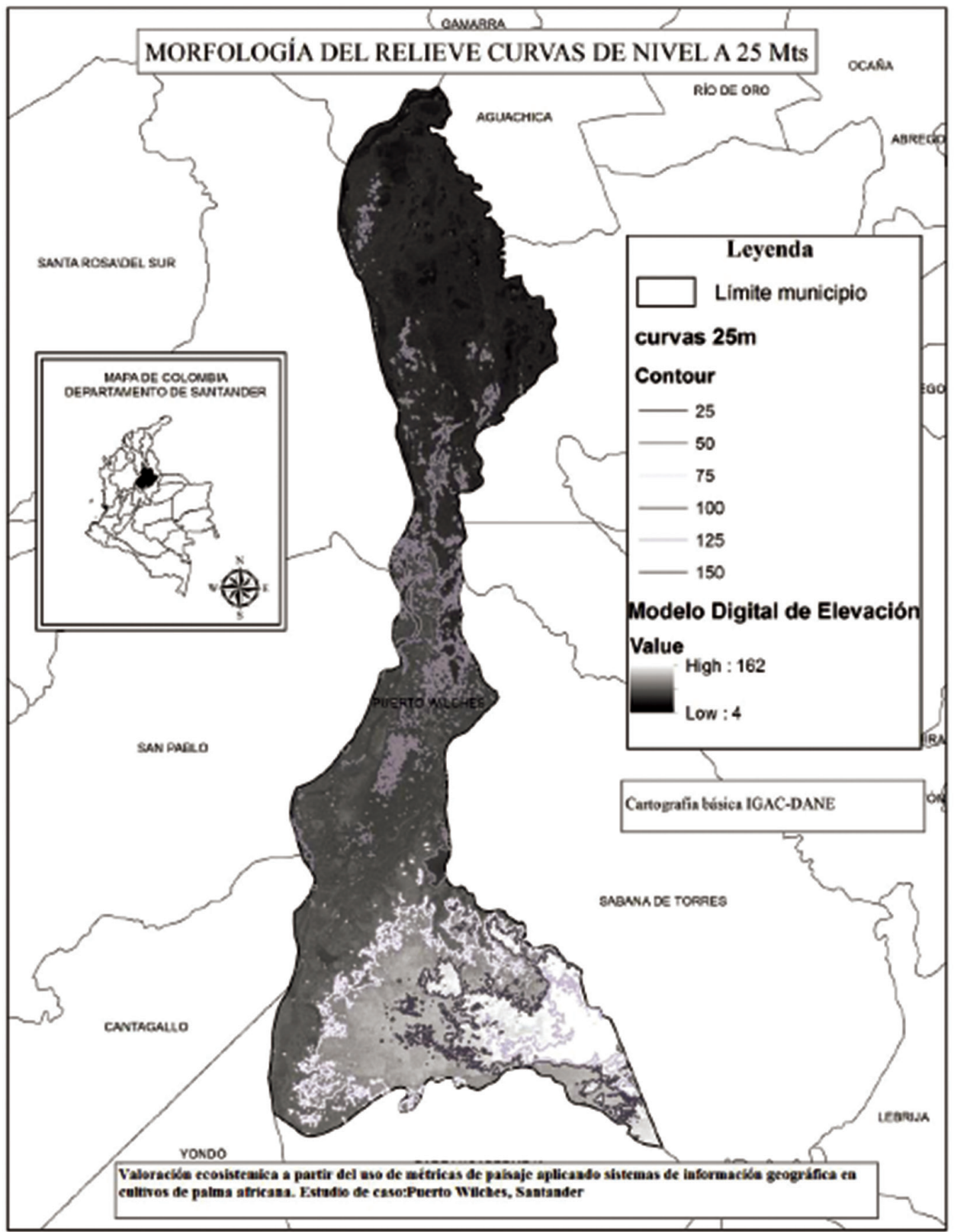

Figura 3. Mapa de morfología del relieve en Puerto Wilches

La valoración subjetiva se realizó mediante la sobreposición de los mapas correspondientes a 1987 y 2015, con lo cual se generó el mapa de ganancia y pérdida de cobertura natural relacionada en la
(Figura 4). Lo anterior permitió determinar el grado de artificialización del territorio con el valor representado por la categoría de pérdida de cobertura natural evaluado en el lapso de 1987 a 2015 (Tabla 4). 


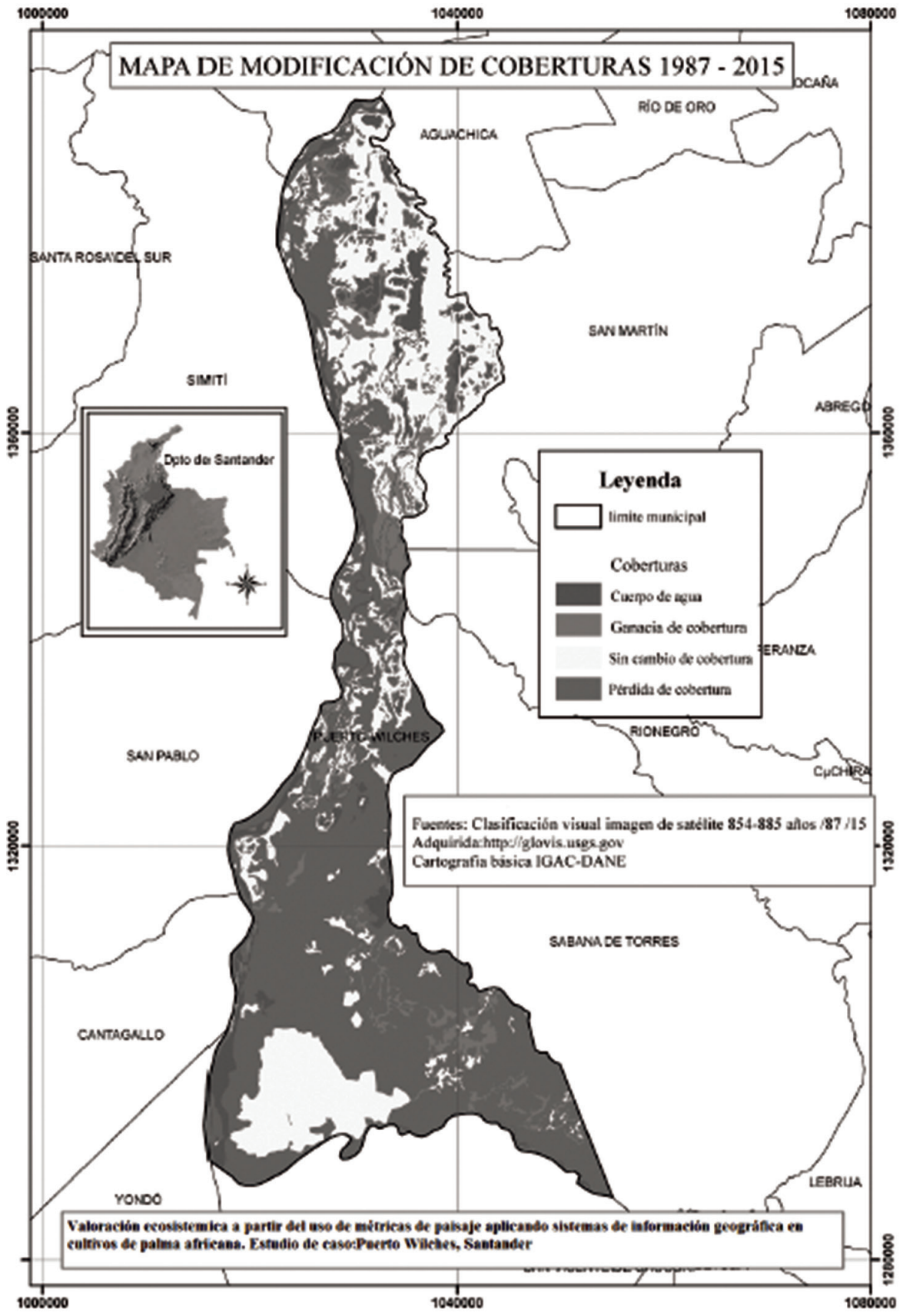

Figura 4. Mapa de transformación paisajística categorizada

Tabla 4. Porcentaje de representatividad de coberturas

\begin{tabular}{l|c}
\hline Categorización & Representatividad \\
\hline Cuerpo de agua & $5.6 \%$ \\
\hline Ganancia de Cobertura natural & $9.8 \%$ \\
\hline perdida de Cobertura natural & $64.5 \%$ \\
\hline Sin cambio de cobertura & $20.1 \%$ \\
\hline
\end{tabular}


La calificación asignada a las unidades del pai- obteniendo un resultado del $49.6 \%$ grado medio, sesaje permitió la categorización de calidad visual, guida de $26.2 \%$ para bajo y alta del $24 \%$ (Figura 5 )

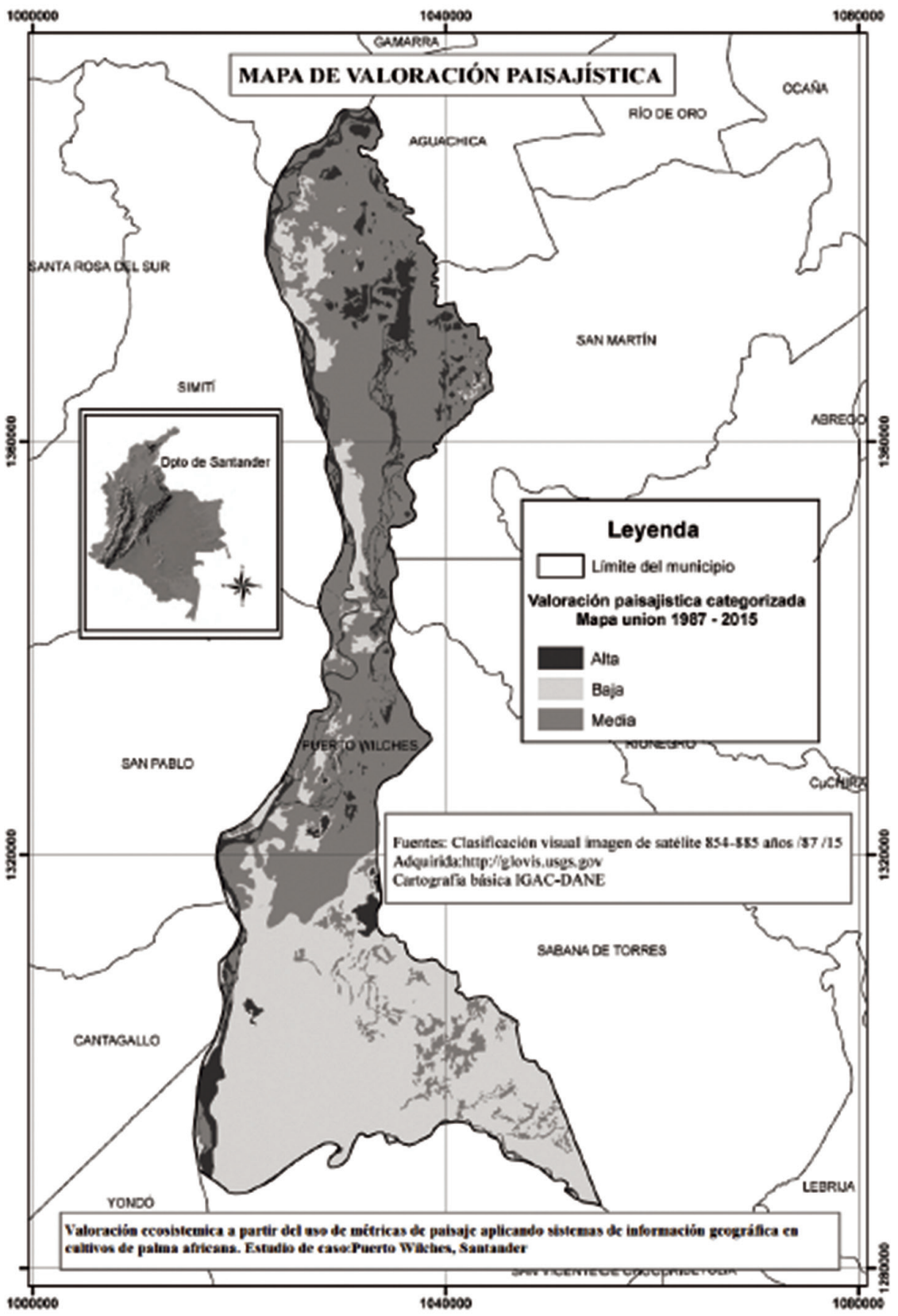

Figura 5. Mapa de valoración paisajística por calidad visual

Por último el análisis de los resultados obtenidos por dominancia de cobertura a partir de la clasificación visual realizada a las imágenes de satélite años 1987-2015, permitió reconocer que existen alteraciones paisajísticas contundentes en el territorio de Puerto Wilches, las cuales se evidencian en los porcentajes de representatividad obtenidos en el periodo de estudio (Tabla 5). Los cambios se originan principalmente por la implementación de los monocultivos de palma africana, el aumento se relaciona en un $30.9 \%$ en el lapso de 1987-2015 (Figura 6). Donde en 2015 el aumento acelerado de la palma africana adquiere el valor más representativo para 2015. 

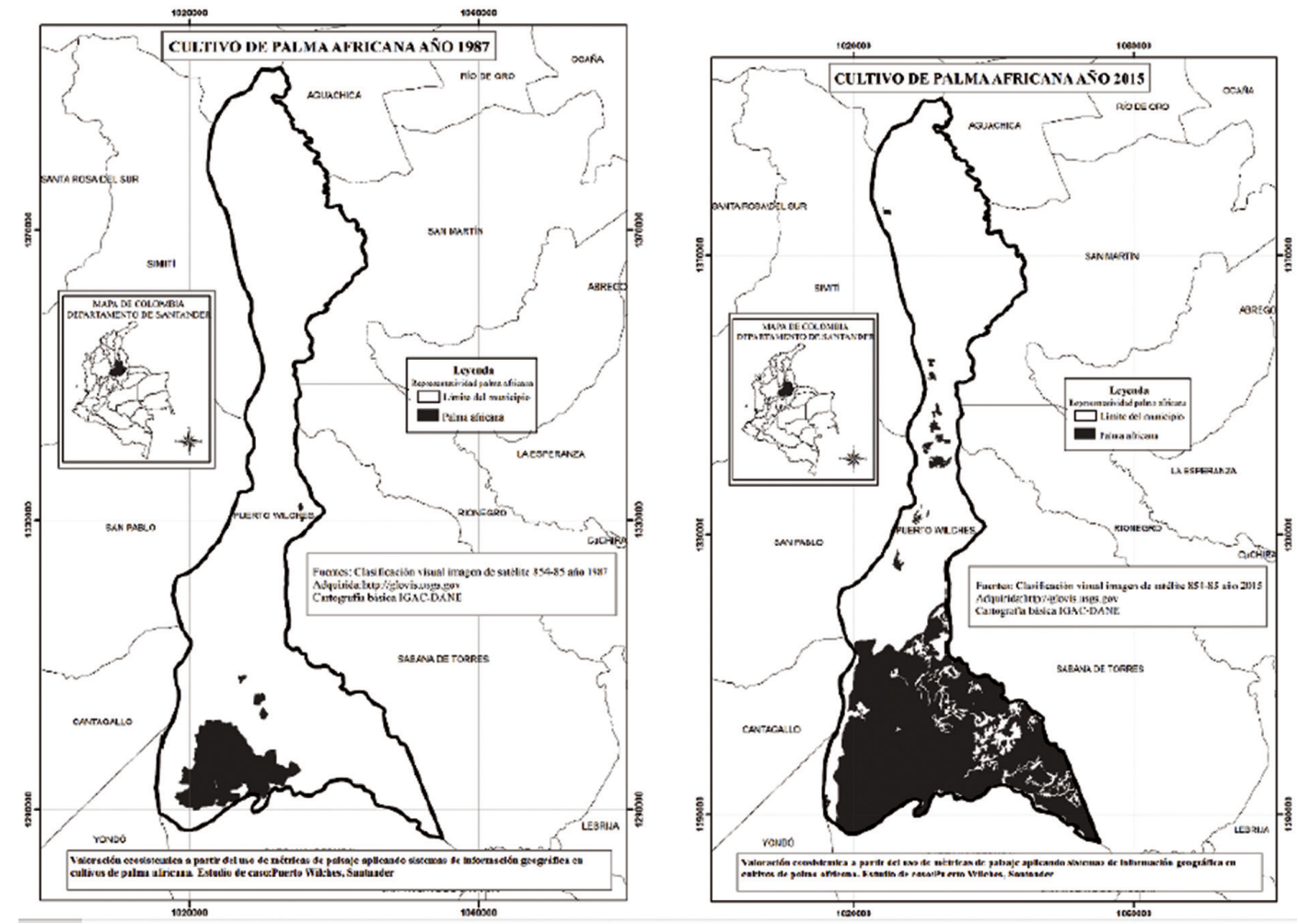

Figura 6. Mosaico de representatividad de la palma africana a) cultivo de palma africana año 1987 b) cultivo de palma africana año 2015

Tabla 5. Representatividad de unidades de paisaje

\begin{tabular}{l|c|c}
\hline Año & Cobertura representativa de la época & Porcentaje de representatividad \\
\hline 1987 & Zona pantanosa & $30.3 \%$ \\
\hline 2015 & Palma africana & $38.6 \%$ \\
\hline
\end{tabular}

\section{Discusión y conclusiones}

En relación a la valoración del paisaje dentro de las diversas metodologías para el proceso de valoración del paisaje se logró converger en criterios específicos de dos metodologías para analizar la zona en estudio, para lo cual la valoración se realizó desde un enfoque de servicio ambiental con base en elementos muy específicos sobre las imágenes satelitales como lo son la escala definida y temporadas de toma diferentes causal de la variación de algunas coberturas, así mismo esta implementación metodológica no permitió dilucidar sobre los efectos de las interacciones y sinergias producidas en el territorio evaluado.
En ese contexto, la valoración paisajística aunada con tecnología satelital aporta en la evaluación del territorio pero sin duda alguna el estudio del paisaje suscita múltiples interrelaciones en el ambiente físico-biótico los cuales requieren de algunos componentes tales como armonía, variedad, disponibilidad, que admitan la apreciación de dinámicas existentes entre ellas.

Para el proceso de análisis de paisaje se tuvieron en cuenta diferentes características, principalmente las relacionadas con estructura, funcionalidad y cambio (Forman \& Godron, 1986), con los cuales se generaron indicadores que permitieron evidenciar la 
transformación del municipio década a década dada por actividades netamente antrópicas como son las plantaciones de diferentes tipos entre ellos siendo el más relevante la palma africana, interfiriendo así, en la estructura ecológica, que afecta las condiciones de diversificación, naturalidad, calidad ambiental e integración antrópica inadecuada. En efecto, la presión ambiental se ha originado por la búsqueda de nuevas alternativas energéticas para dar cumplimiento a los múltiples requerimientos, afectando la seguridad alimentaria de la población y haciendo insostenible este tipo de métodos de cultivo.

En efecto, los resultados obtenidos demuestran que los efectos producidos en la fragmentación paisajística son producto de la manera insostenible como se explotan los recursos que originan la ruptura de las ecosistémica y alteran el arquetipo paisajístico, acrecentado por la industria a escala local.

Por lo anterior, debe existir una relación entre la investigación y conocimiento de los ecosistemas regionales para dar paso a la gestión responsable sobre los recursos naturales, este compromiso recae en la institucionalidad y las industrias, las cuales deben tener en cuenta la importancia de la biodiversidad y su relación ecosistémica, para enfrentar el desarrollo sin afectar el ambiente de las regiones.

\section{Agradecimientos}

La autora agradece a la Universidad Piloto de Colombia, facultad de Ciencias Ambientales, programa de Administración Ambiental.

\section{Literatura citada}

1. Alcaldía Municipal de Puerto Wilches Santander. (2012). Esquema de Ordenamiento Territorial Puerto Wilches Santander. (pp 32, 47). Recuperado de http:// www.puertowilches-santander.gov.co/index.shtml

2. Cañas, I. (1995). Introducción al paisaje. Unicopia. MadridCouncil of Europe. (2000). European Landscape Convention. Florence.

3. Dunn, M.C. (1974) Landscape evaluation techniques: an appraisal and review of the literature. Centre for Urban and Regional Studies, University of Birminghan, Birminghan, United Kingdom. 123 pp.

4. ESRI. (2011). ArcGis Desktop: Release 10.1. Redlans, CA: Enviromental Sistem Research Institute.

5. Forman, K. \& Godron, M. (1986) Landscape ecology. John Wiley and Sons, New York, New York, USA. 619 pp

6. Gobierno de la Ciudad. (2012). Plan de Desarrollo 2012-2015 "primero la gente" (pp. 45, 48). Recuperado de http://puertowiches-santander.gov.co/apc-aa-files/ Plan_de_desarrollo_Puerto_Wilches.pdf

7. Gómez, A. (2012). El paisaje: Diseño de una metodología para su análisis, diagnóstico, planificación e inclusión en los procesos de toma de decisiones. (Tesis Doctoral). Universidad Politécnica de Madrid, Madrid. Recuperado de http://oa.upm.es/13532/2/ALEJANDRO_GOMEZ_VILLARINO_2.pdf

8. Gómez, J. (1995). La Geografía y la ordenación del territorio: algunas cuestiones teóricas y prácticas. lurralde. 18, 7-20.

9. González, A. \& Moñino, M. (2000). Fotointerpretación geomorfológica aplicada al estudio de la evolución del relieve. Enseñanza de las Ciencias de la Tierra, 8(1), 23-31.

10. Hoechstetter S., U. Walz, L. H. Dang \& N. X. Thinh (2008), "Effects of topography and surface roughness in analyses of landscape structure a proposal to modify the existing set of landscape metrics", in Landscape Online, no. 1, pp. 1-14.

11. Instituto de Hidrología, Meteorología y Estudios Ambientales IDEAM, Instituto Geográfico Agustín Codazzi IGAC, \& CORMAGDALENA. (2008) Metodología CORINE Land Cover Adaptada para Colombia escala 1:100.000, Bogotá, 2008.

12. León Mata, G. D. de, Pinedo, A. \& Martínez, J. H. (2014), Aplicación de sensores remotos en el análisis de la fragmentación del paisaje en Cuchillas de la Zarca, México, Investigaciones Geográficas, Boletín, núm. 84, Instituto de Geografía, UNAM, México, pp. 42-53, doi: dx.doi.org/10.14350/rig.36568

13. McGarigal K. \& S. A. Cushman (2005), The gradient concept of landscape structure, in Wiens, J. and M. Moss (comps.), Issues and perspectives in landscape ecology, Cambridge University Press, Cambridge, pp. 112-119. 
14. Másmela, P. (2010), El paisaje como elemento de la ordenación territorial, un análisis de paisaje desde su enfoque visual en el borde centro oriental de Medellín, Colombia. (Tesis de Maestría). Universidad Nacional de Colombia, Medellín. Recuperado de www.bdigital. unal.edu.co/3734.pdf

15. MOPT. (1993) Guía metodológica para el estudio del medio físico y la planificación. Ministerio de Obras Públicas y Transporte, Series Monográficas, Madrid, España. 809 pp.
16. Muñoz, A. (2004). La evaluación del paisaje: una herramienta de gestión ambiental. Revista chilena de historia natural, 77(1),139-156. https://dx.doi.org/10.4067/ S0716-078X2004000100011

17. Serrano, G. D. (2015), Valoración escénica de paisaje periurbano con utilidad en planeamiento territorial. Estudio de caso en la Región Metropolitana de Barcelona", Investigaciones Geográficas, Boletín, núm. 88, Instituto de Geografía, UNAM, México, pp. 109-121, dx.doi.org/10.14350/rig.45090.
Conflicto de Intereses Los autores declaran no tener ningún conflicto de intereses

Recibido: 14 de abril de 2016 Aceptado: 26 de mayo de 2016 